\title{
Slow Gelation of Titanium(IV) with Partially Hydrolyzed Polyacrylamide. Crosslinking Reaction and Gel Properties
}

\author{
Wensheng $\mathrm{CAI}^{\dagger}$ and Ronghua HUANG \\ Polymer Research Institute, Sichuan University, Chengdu 610065, P. R. China
}

(Received November 6, 2000; Accepted January 11, 2001)

\begin{abstract}
The gelation of metallic crosslinking agent titanium(IV) (Ti(IV)) with partially hydrolyzed polyacrylamide (HPAM) is studied. Factors effecting the crosslinking reaction are discussed and the dynamic properties of gel are examined. The results indicate that crosslinking of Ti(IV) with HPAM is delayed at low concentrations of polymer and the titanium tartrate. The gelling of Ti(IV)-HPAM is a strong function of titanium/tartaric acid molar ratio, HPAM concentration, initial solution $\mathrm{pH}$ value, solution salinity, and hydrolysis degree of HPAM. The gel strength depends on Ti(IV) concentration in a particular way, after a maximum Ti(IV) concentration is reached gel strength decreases. The salt $\mathrm{NaCl}$ can accelerate the gelling rate of Ti(IV)-HPAM. The crosslinking mechanism of $\mathrm{Ti}(\mathrm{IV})$ with HPAM is proposed. Ti(IV)-HPAM gel can hold its strength at moderate temperature $\left(50^{\circ} \mathrm{C}\right)$ for a long time which is suitable to be used in a moderate temperature oil reservoir.

KEY WORDS Titanium / Tartaric Acid / Partially Hydrolyzed Polyacrylamide (HPAM) / Metal Ion Crosslinking Agents / Enhanced Oil Recovery /
\end{abstract}

Polymer gels have been extensively studied in the last few decades because of their great aspects in both theoretical field and industry applications. ${ }^{1-5}$ Particularly, in the oil industry, polymer gels are used broadly in Enhanced Oil Recovery (EOR), such as reducing water in the production of oil well, ${ }^{6}$ profile modification, ${ }^{7}$ and in depth treatment. ${ }^{8}$ In the in-situ gelation technology, ${ }^{7-8}$ polymer solution and the crosslinker are mixed on ground before being injected into wellbore and the porous reservoir rock. The solutions become crosslinked insitu under reservoir and the formed gel is used for profile modification or depth treatment depending on the strength of the gel. The gelation time can be controlled from minutes to weeks by varying the formulation parameters. In addition, these gels are relatively inexpensive because they typically contain about $95-99.7 \mathrm{wt} \%$ of water, with the remainder being low cost chemicals. ${ }^{9}$ The representative polymers involved in this gelation system are either partially hydrolyzed polyacrylamide (HPAM) or biopolymer Xanthan gum. ${ }^{10}$ Transition metal ions such as $\mathrm{Cr}^{3+}, \mathrm{Zr}^{4+}, \mathrm{Al}^{3+}$ are often used as crosslinking agents for the gelling. ${ }^{5,11-17}$ The systems with $\mathrm{Cr}^{3+}$ and $\mathrm{Al}^{3+}$ as crosslinking agents receive particular attention.

The representative aluminum crosslinker is aluminum citrate, which has been on a commercial scale with both technical and economic success, but the $\mathrm{Al}^{3+}$ /polymer gels are only stable at low $\mathrm{pH}$ and low temperature, hard brines and neutral $\mathrm{pH}$ condition in the oilfield are detrimental for sodium-aluminate/polymer system. ${ }^{12}$ Recently, more interests are concentrated on Cr-HPAM gel system..$^{13-15}$ Unfortunately, the negative healthy effects of chromium(VI) which is reported to be carcinogenic, is environmental unacceptable. $\mathrm{Cr}^{3+}$ is relatively low toxic, $\mathrm{Cr}$ (III) compounds such as $\mathrm{CrCl}_{3}$ or $\mathrm{Cr}\left(\mathrm{NO}_{3}\right)_{3},{ }^{13} \mathrm{Cr}$ acetate ${ }^{14}$ have been studied as crosslinking agents. But the application of this technology to in-depth treatment of matrix rock is limited because these chromium(III)/polymer crosslinking are usually too rapid. In addition, gelation of zirconium(IV) with polyacrylamide and scleroglucan are also studied, ${ }^{16,17}$ the retardation and weakening of crosslinking are obtained by adding zirconium lactates into the polymer solutions.

Due to the shortcoming of $\mathrm{Al}^{3+}$ and $\mathrm{Cr}^{3+}$, metal crosslinking agents which are stable at neutral $\mathrm{pH}$ condition and slowly gelled with HPAM are needed. Compared to the expensive zirconium, titanium is a relatively common metal that is the ninth most abundant element in the earth crust. ${ }^{18}$ Titanium has four valence electrons and the most stable oxidation state of titanium is $\mathrm{Ti}^{4+}$. In this paper, to our knowledge, the gelation of HPAM with titanium tartrate complexes is studied for first time. Factors effecting the gelation of Ti(IV) with HPAM are discussed and the rheological properties of Ti(IV)-HPAM gel are examined. Explanations about the observed behaviors are also given out.

\section{EXPERIMENTAL}

\section{Materials}

Titanium(IV) sulfate, sodium hydroxide, sodium chloride and tartaric acid were used as received from Chengdu Chemical Agents Company (China). The HPAM(I) employed in these studies (from Daqing Petroleum Inc., China) had a $M_{\mathrm{w}}$ of $1.7 \times 10^{7}$ (viscosity determination) and was $22.5 \%$ hydrolyzed (titration determination). Another HPAM(II) with $M_{\mathrm{w}} 1.0 \times 10^{7}$, with $5 \%$ hydrolysis degree was hydrolyzed further to $15 \%, 22 \%$, $42 \%$ in alkaline solution (titration determination) for the study of effect of hydrolysis degree on the gelation.

\section{Preparing Titanium Tartrate Crosslinking Agent}

Titanium tartrate was prepared by reaction of tartaric acid with titanium sulfate. Tartaric acid was added into

\footnotetext{
${ }^{\dagger}$ To whom correspondence should be addressed (E-mail: wscai@eng.auburn.edu).
} 
the titanium sulfate solution $(0.1 \mathrm{~mol} \mathrm{~L})$ at appropriate stoichiometry (the mole ratios of titanium here were in $\mathrm{TiO}_{2}$ equivalent). The solution was stored at room temperature for few days to form stable titanium tartrate complexes. The $\mathrm{pH}$ values of the solution were adjusted by $0.1 \mathrm{~N} \mathrm{NaOH}$ solution.

\section{Gel Synthesis}

HPAM(I) stock solution was mixed with titanium tartrate crosslinking agent and sodium chloride in a tube at appropriate feed ratio, then the tube was sealed and stored in a oven at $50^{\circ} \mathrm{C}$. The gel strength was characterized by the apparent viscosity of gel solution which was measured by Brookfield viscometer $\left(6.9 \mathrm{~s}^{-1}\right.$ shear rate, $25^{\circ} \mathrm{C}$ ). In the experiments, all the mixture were fixed with formulation of $400 \mathrm{ppm}$ HPAM, $10000 \mathrm{ppm} \mathrm{NaCl}$ and $125 \mathrm{ppm} \mathrm{Ti}(\mathrm{IV})$-tartrate except for special indication.

\section{Dynamic Measurement}

The rheometer RheoStress RS 100 of Haake was used to measure the viscoelastic properties of the Ti(IV)HPAM gel and HPAM dilute solution. All experiments were conducted at $25^{\circ} \mathrm{C}$.

\section{RESULTS AND DISCUSSION}

\section{Stability of Titanium Tartrate}

Titanium(IV) sulfate $\left(\mathrm{Ti}\left(\mathrm{SO}_{4}\right)_{2} \cdot 9 \mathrm{H}_{2} \mathrm{O}\right)$ is highly acidic, it is only stable at low $\mathrm{pH}$, but at neutral and alkaline conditions, the hydrolysis of Ti(IV) ions results in precipitation from solution. ${ }^{18}$ The hydrolysis of Ti(IV) can be illustrated as below:

$$
\begin{aligned}
& {\left[\mathrm{Ti}\left(\mathrm{H}_{2} \mathrm{O}\right)_{6}\right]^{4+} \Leftrightarrow\left(\left[\mathrm{Ti}\left(\mathrm{H}_{2} \mathrm{O}\right)_{5} \mathrm{OH}\right]^{3+}+\mathrm{H}^{+}\right.} \\
& {\left[\mathrm{Ti}\left(\mathrm{H}_{2} \mathrm{O}\right)_{5} \mathrm{OH}\right]^{3+} \Leftrightarrow\left[\mathrm{Ti}\left(\mathrm{H}_{2} \mathrm{O}\right)_{4}(\mathrm{OH})_{2}\right]^{2+}+\mathrm{H}^{+}} \\
& {\left[\mathrm{Ti}\left(\mathrm{H}_{2} \mathrm{O}\right)_{4}(\mathrm{OH})_{2}\right]^{2+} \Leftrightarrow\left[\mathrm{Ti}\left(\mathrm{H}_{2} \mathrm{O}\right)_{3}(\mathrm{OH})_{3}\right]^{+}+\mathrm{H}^{+}} \\
& {\left[\mathrm{Ti}\left(\mathrm{H}_{2} \mathrm{O}\right)_{3}(\mathrm{OH})_{3}\right]^{+} \Leftrightarrow\left[\mathrm{Ti}(\mathrm{OH})_{4}\right]^{+}+2 \mathrm{H}_{2} \mathrm{O}+\mathrm{H}^{+}}
\end{aligned}
$$

On the other hand, Ti(IV) can also react with oxyacids to form complexes with different shape and stability. When tartaric acid is added into the titanium sulfate solution, the organic acid will replace $\mathrm{H}_{2} \mathrm{O}$ as ligand to coordinate with $\mathrm{Ti}(\mathrm{IV})$, forming more stable complexes. The stability of titanium tartrate can be controlled by the feed ratio of titanium to tartaric acid.

Table $\mathrm{I}$ is the precipitation $\mathrm{pH}$ values of titanium tartrate after preparing for different time. It is showed that the coordination between Ti(IV) and tartaric acid is a thermodynamic process. It takes time to form stable complexes. With increase of tartaric acid in feed ratios, the formation of stable titanium tartrate complexes becomes faster. When the molar ratio of the Ti(IV)/tartaric acid is 1:0.8, it takes three days to form stable complexes which shows no precipitation when titrated by $\mathrm{NaOH}$; as the tartaric acid in feed ratios of $\mathrm{Ti}(\mathrm{IV}) /$ tartaric acid are increased to $1: 1$ and $1: 1.2$, respectively, it only takes two days to form stable complexes that show no precipitation when titrated by $\mathrm{NaOH}$.

Figure 1 is the comparison of titration curves of Titanium sulfate and titanium tartarate by $\mathrm{NaOH}$. It is showed that the two Titanium(IV) in different format have different stability. With increase of $\mathrm{NaOH}$ used, the $\mathrm{pH}$ value of titanium tartrate solution increases

\begin{tabular}{|c|c|c|c|}
\hline \multirow[t]{2}{*}{ Time/day } & \multicolumn{3}{|c|}{$\begin{array}{l}\text { The molar ratios of titanium to tartaric acid } \\
\qquad \mathrm{mol} / \mathrm{mol}\end{array}$} \\
\hline & $1: 0.8$ & $1: 1$ & $1: 1.2$ \\
\hline 0.5 & 3.50 & 4.42 & 5.00 \\
\hline 1 & 4.10 & 9.80 & 12.60 \\
\hline 2 & 5.12 & - & - \\
\hline 3 & - & - & - \\
\hline
\end{tabular}
sharply more early than that of titanium sulfate solu-
Table I. The variation of precipitation $\mathrm{pH}$ values of titanium tartrate titrated by $\mathrm{NaOH}$ at different time

—: No precipitation occurs.

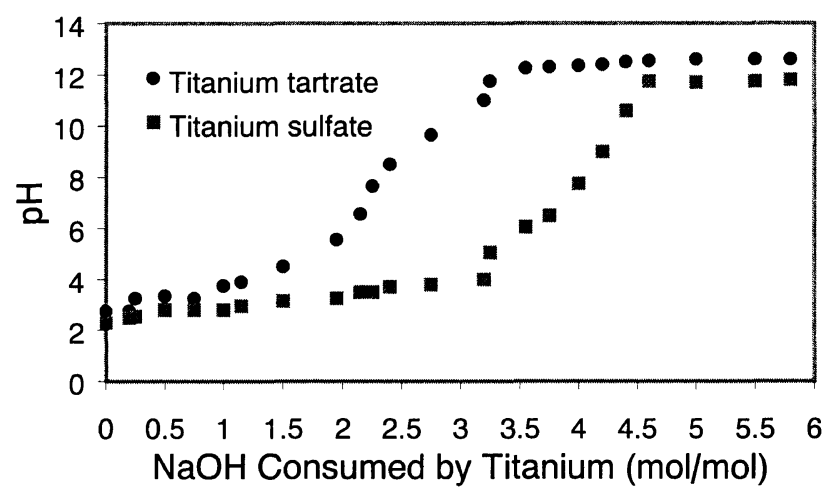

Figure 1. The titration curves of titanium sulfate and titanium tartrate.

tion. When the amount of $\mathrm{NaOH}$ increased from 2 to $3.25 \mathrm{~mol} \mathrm{NaOH} / \mathrm{mol} \mathrm{Ti}(\mathrm{IV})$, the solution $\mathrm{pH}$ of titanium tartrate increases rapidly from 5.6 to 12 ; meanwhile, the $\mathrm{pH}$ of titanium sulfate solution does not change much. With further adding of $\mathrm{NaOH}$, the $\mathrm{pH}$ of titanium sulfate solution begins to increase sharply. This is due to that titanium tartrate complexes are more stable than titanium sulfate. When $\mathrm{NaOH}$ is added into the titanium sulfate solution, the $\mathrm{OH}^{-}$groups will first replace $\mathrm{H}_{2} \mathrm{O}$ as ligands to coordinate with Ti(IV), causing hydrolysis of titanium, most of $\mathrm{OH}^{-}$are consumed as ligands, so the $\mathrm{pH}$ value of the solution increases slowly. In the titanium tartrate solution, because titanium tartrate is relatively stable, exchanges between the added $\mathrm{OH}^{-}$and tartaric acid are slow, the majority of initially added $\mathrm{OH}^{-}$could not replace tartaric acid ligands to coordinate with titanium, these $\mathrm{OH}^{-}$ions make the $\mathrm{pH}$ value of solution increase sharply more early.

\section{Effect of Molar Ratio of Titanium / Tartaric Acid}

The process of HPAM crosslinked by Ti (IV) ions is in fact a ligands exchange process between tartarate and carboxyl groups of HPAM. The crosslinking mechanism can be written schematically as follows:

$$
\begin{gathered}
\underset{+\mathrm{mNa}^{+}}{\mathrm{m}(\mathrm{P}-\mathrm{COONa})}+\mathrm{Ti}_{x}(\mathrm{~L})_{n} \rightarrow \mathrm{Ti}_{x}\left(\mathrm{PCOO}^{-}\right)_{m}(\mathrm{~L})_{n-m}+\mathrm{mL}^{-} \\
\mathrm{L}^{-}+\mathrm{Na}^{+} \rightarrow \mathrm{Na}^{+} \mathrm{L}^{-}
\end{gathered}
$$

where $\mathrm{P}$ is the polymer chain, $\mathrm{L}$ is the ligands, and the $\mathrm{m}$ should be great enough to bridge polymer chains together.

During the crosslinking reaction, Ti(IV) ions are released from titanium tartrate complexes to form new 
complexes with carboxyl groups of HPAM, further causing crosslinking between polymer chains through Ti(IV) bridge. The stability of titanium tartrate complexes influence both releasing rate of $\mathrm{Ti}(\mathrm{IV})$ ions and the crosslinking rate between titanium and HPAM. By controlling the stability of TI(IV) tartrate, the Ti(IV)-HPAM gelling rate can be controlled. In Figure 2, with decrease of tartaric acid in feed ratio of titanium/tartaric acid, the Ti(IV)-HPAM gelling rates increase. For titanium tartrate with molar ratio of titanium/tartaric acid $1: 1.5$, there is no obvious gelation within the first $25 \mathrm{~h}$; as the ratio of titanium/tartaric acid increased to $1: 0.5$, the gel strength increases from $6.4 \mathrm{mPa}$ s to $525 \mathrm{mPa}$ s within $12 \mathrm{~h}$. This confirms that the more stable the titanium tartrate, the more delayed the gelling. For convenience, all the titanium tartrate crosslinking agents used in the below experiments are fixed with molar ratio of $\mathrm{Ti}(\mathrm{IV}) /$ tartaric acid as $1: 0.8$.

\section{$p H$ of the Solution}

Figure 3 shows the effect of initial solution $\mathrm{pH}$ on the Ti(IV)-HPAM gelling rate. In the neutral solution $(\mathrm{pH}=$ 6.59), Ti(IV)-HPAM is gelling fast, the gel strength reaches $1520 \mathrm{mPa}$ s after gelling for $60 \mathrm{~h}$; while in the acidic solution $(\mathrm{pH}=3.74)$, no gelation happens. In the weak alkaline solution, precipitation happens which should be due to the hydrolysis of titanium. The solution $\mathrm{pH}$ influences the gelling rate of Ti(IV)-HPAM by affecting Ti(IV) releasing rate from titanium tartrate complexes. In the acidic solution, $(\mathrm{pH}=3.74)$, titanium tartrate complexes are very stable, there are not enough Ti(IV) ions produced to form Ti(IV)-HPAM gelation; at the weak acid solution ( $\mathrm{pH} 4.95-6.59$ ), the Ti(IV)/tartaric acid complexes become less stable, more Ti(IV) ions are released to crosslink with HPAM molecular chains, so the gel strength increases rapidly with time. The results indicate that a suitable solution $\mathrm{pH}$ range for $\mathrm{Ti}(\mathrm{IV})^{-}$ HPAM crosslinking is between $3.74-6.59$.

\section{Effect of HPAM Concentration}

The influence of HPAM concentration on the HPAM gelation is showed in Figure 4. The gel strength increases with increase of polymer concentration. This is due to that at high polymer concentration, it is easier to form intermolecular crosslinking through Ti(IV) bridge. In the dilute solution, polymer chains are so far away each other that it is hard to form intermolecular crosslinking. There is no obvious gelation when polymer concentration is below $300 \mathrm{ppm}$.

\section{Influence of Titanium Concentration}

The titanium concentration, $C_{\mathrm{Ti}}$, influences the gelling of Ti(IV)-HPAM in a particular way. The gel strength increases first with increasing of $C_{\mathrm{Ti}}$, reaching maximum at $C_{\mathrm{Ti}}$ of $250 \mathrm{ppm}$, then goes down at higher $C_{\mathrm{Ti}}$ (Figure 5 ). Same trend was observed for zirconium-scleroglucan system. ${ }^{16}$ During the crosslinking process, Ti(IV) ions dissociate first from titanium tartrate complexes before crosslinking with carboxyl groups of HPAM, after the dissociation, there is a competition between crosslinking with HPAM and formation of higher titanium polynuclear species through oxo-bridges. ${ }^{18}$ At higher $C_{\mathrm{Ti}}$, the degree of forming polynuclear is greater, which reduces

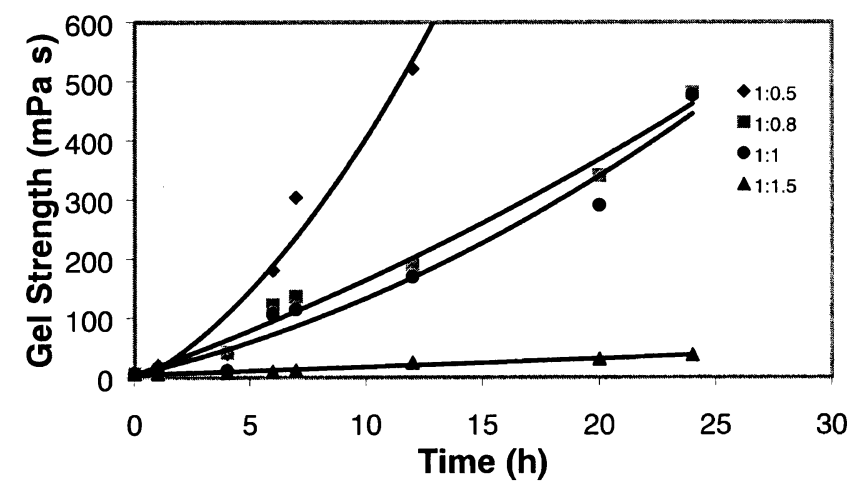

Figure 2. Effect of molar ratio of titanium to tartaric acid on the gelling of $\mathrm{Ti}(\mathrm{IV})-\mathrm{HPAM}$, the $\mathrm{pH}$ of solution is 4.95 .

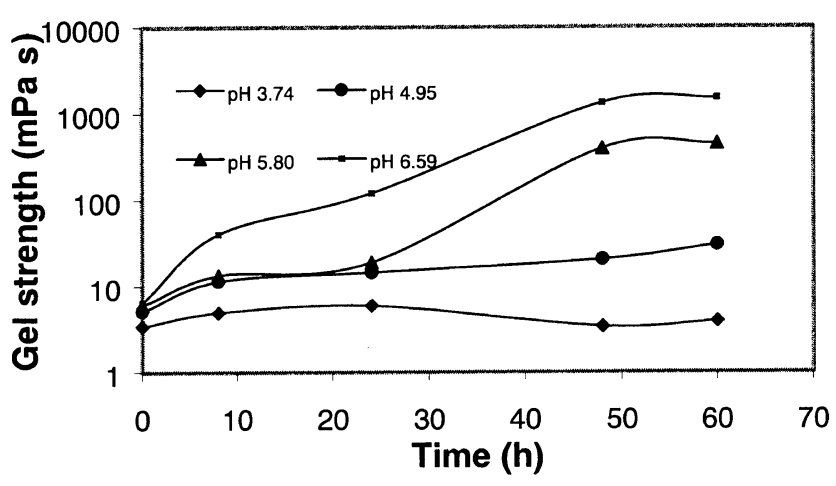

Figure 3. Effect of solution $\mathrm{pH}$ on the gelling of Ti(IV)-HPAM.

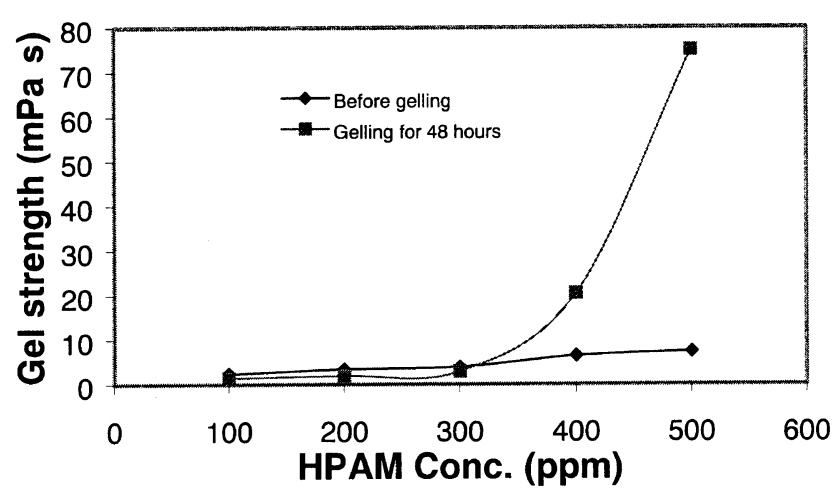

Figure 4. The influence of HPAM concentration on the gelling of Ti(IV)-HPAM after gelled for $48 \mathrm{~h}$, the Ti(IV) concentration is 110 ppm, the $\mathrm{pH}$ of the solution is 4.95 .

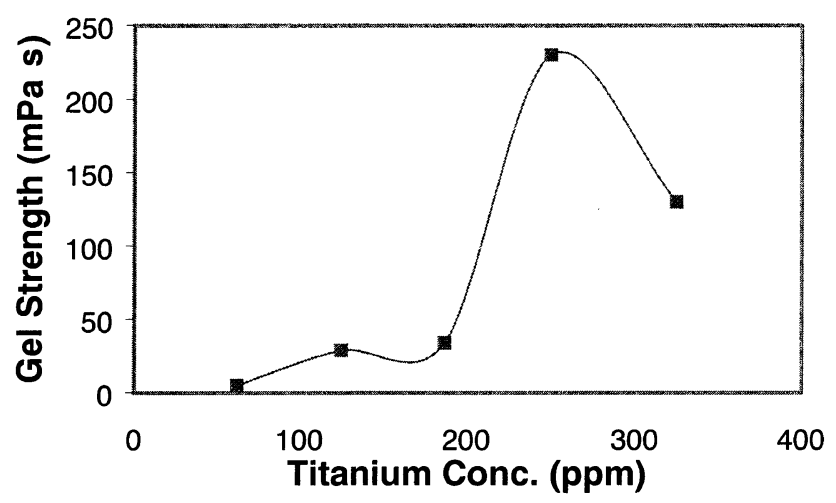

Figure 5. The influence of $\mathrm{Ti}(\mathrm{IV})$ concentration on the gel strength after gelling for $24 \mathrm{~h}$, the $\mathrm{pH}$ of solution is 4.95 . 
the effective crosslinkage between titanium and carboxyl groups of HPAM, thus decreasing the gel strength of Ti(IV)-HPAM.

\section{Effect of Salinity}

The gelation reaction between titanium and HPAM strongly depends on solution salinity (Figure 6). In free salt water, no gelation happens even after $80 \mathrm{~h}$ at $50^{\circ} \mathrm{C}$. In salt solution, gelation take places and increases with $\mathrm{NaCl}$ concentration. This is good for application in most of oil reservoirs which have hard brines. Equations 1 and 2 indicate that the added $\mathrm{Na}^{+}$can form stable sodium tartrate, which accelerates the ligand exchange rate of tartaric acid with HPAM.

\section{Effect of Hydrolysis Degree of Polyacrylamide}

In this experiment, HPAM(II) is hydrolyzed into different hydrolysis degree and then crosslinked by Ti(IV). The effect of hydrolysis degree of HPAM on the gelation of Ti(IV)-HPAM is illustrated in Figure 7. The gel strength displays an interesting dependence on the hydrolysis degree of the HPAM. After gelled for $42 \mathrm{~h}$, the HPAM with $15 \%$ of carboxyl groups has highest gel strength. Higher hydrolysis degree of HPAM also leads decrease of the gel strength. The reason can be explained as below: HPAM is mainly crosslinked through coordination of Ti(IV) with carboxyl groups, the more carboxyl groups in HPAM, the easier to form crosslinkage. But high carboxyl groups also causes intramolecular crosslinking at dilute polymer solution, which decreases the Ti(IV)-HPAM gel strength.

\section{Influence of Gelling Temperature and Time}

Figure 8 is the influence of temperature on gelling of Ti(IV)-HPAM. It appears that the TI(IV)/HPAM gelling rate is favored when temperature increases, but Ti(IV)HPAM gel structure is not stable at high temperate $\left(75^{\circ} \mathrm{C}\right.$ and $\left.90^{\circ} \mathrm{C}\right)$. At $50^{\circ} \mathrm{C}$, after $10 \mathrm{~h}$ of gelling, the gel strength reaches maximum and keeps high strength afterwards. At high temperatures $\left(70^{\circ} \mathrm{C}\right.$ and $\left.90^{\circ} \mathrm{C}\right), \mathrm{Ti}(\mathrm{IV})$ tartrate releases Ti(IV) fast, resulting in fast gelling of Ti(IV)-HPAM, the gel strength increases rapidly at beginning, but soon collapses with further heating. This is because that high temperature causes the hydrolysis of the amide groups of HPAM which leads substantial syneresis of the formed gel. ${ }^{19}$ It is showed that after gelling at $90^{\circ} \mathrm{C}$ for $6 \mathrm{~h}$, the Ti(IV)-HPAM gel strength increases to $59.7 \mathrm{mPa} \mathrm{s}$, but soon collapses abruptly. At $50^{\circ} \mathrm{C}$, the hydrolysis of amide groups of HPAM is slow, the gel can keep its strength for long time. Table II shows that the Ti(IV)-HPAM gel can hold its strength as $145 \mathrm{mPa}$ s under $50^{\circ} \mathrm{C}$ for 58 days. These results suggest that the titanium-HPAM is a weak metal ion crosslinked gel that is suitable for application in a moderate temperature oil reservoir.

\section{Dynamic Test of Titanium-HPAM Gel}

Dynamic test is the rhelogical study of viscoelastic behavior of fluid in which the effect of oscillating stresses or strains on the behavior of the sample is studied. The complex modulus $G^{*}$ represents the substance total resistance against the applied strain.

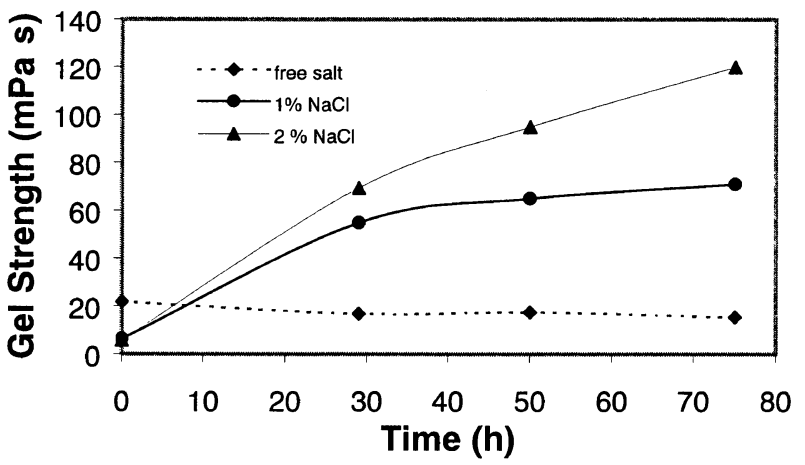

Figure 6. Effect of $\mathrm{NaCl}$ concentration on the gelling kinetics, the $\mathrm{pH}$ of the solution is 4.95 .

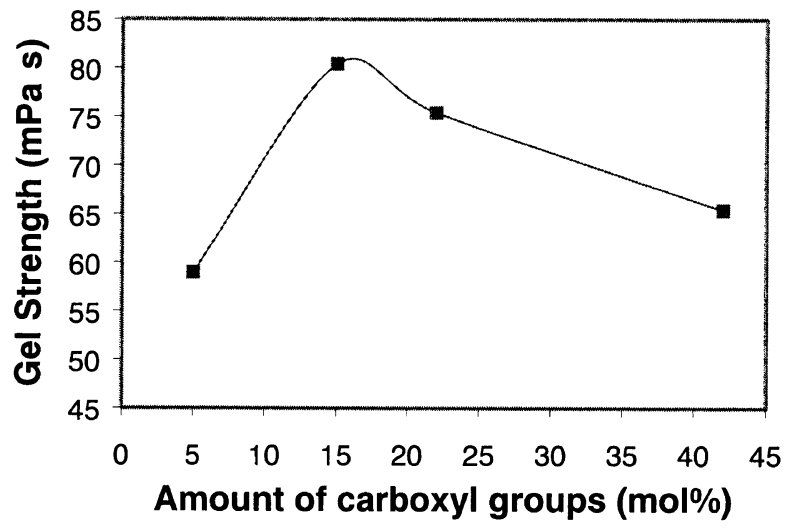

Figure 7. The influence of the hydrolysis degree of HPAM(II) on the gel strength after gelling for $42 \mathrm{~h}$, the concentration of HPAM (II) is $1000 \mathrm{ppm}$ with $20000 \mathrm{ppm} \mathrm{NaCl}$, and the $\mathrm{pH}$ of the solution 5.25 .

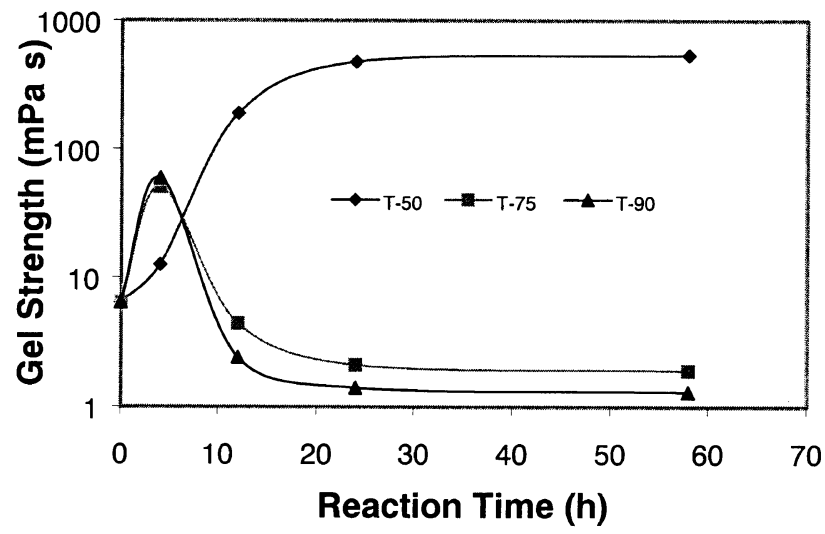

Figure 8. The variation of gel strength of Ti(IV)-HPAM with time at different temperature the $\mathrm{pH}$ of the solution is 5.20.

Table II. The effect of aging time on the Ti(IV)-HPAM gel strength at $50^{\circ} \mathrm{C}$, the $\mathrm{pH}$ of the solution is 6.39

\begin{tabular}{cc}
\hline Time/day & Gel strength $/ \mathrm{mPa}$ s \\
\hline 0 & 6.4 \\
0.54 & 10.2 \\
1.5 & 90.5 \\
10 & 145.1 \\
30 & 143.6 \\
45 & 145.2 \\
\hline
\end{tabular}




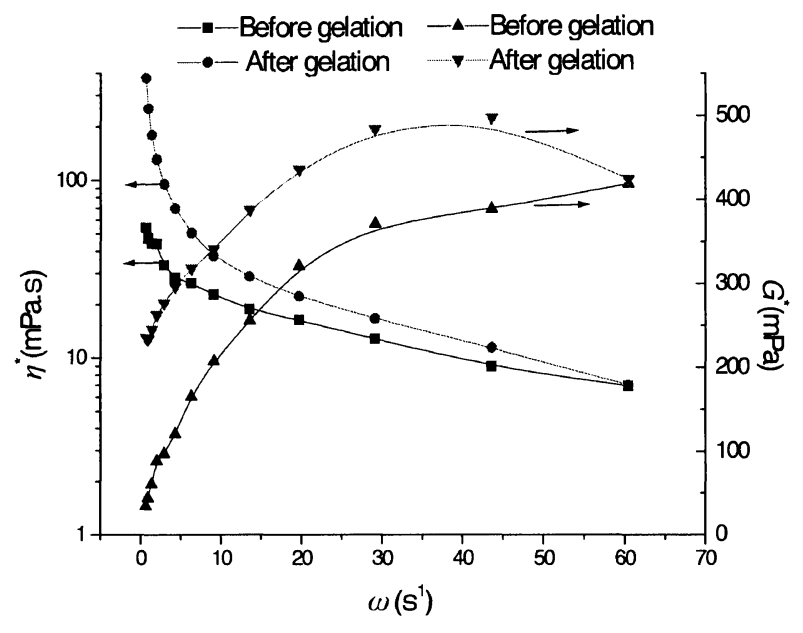

(a)

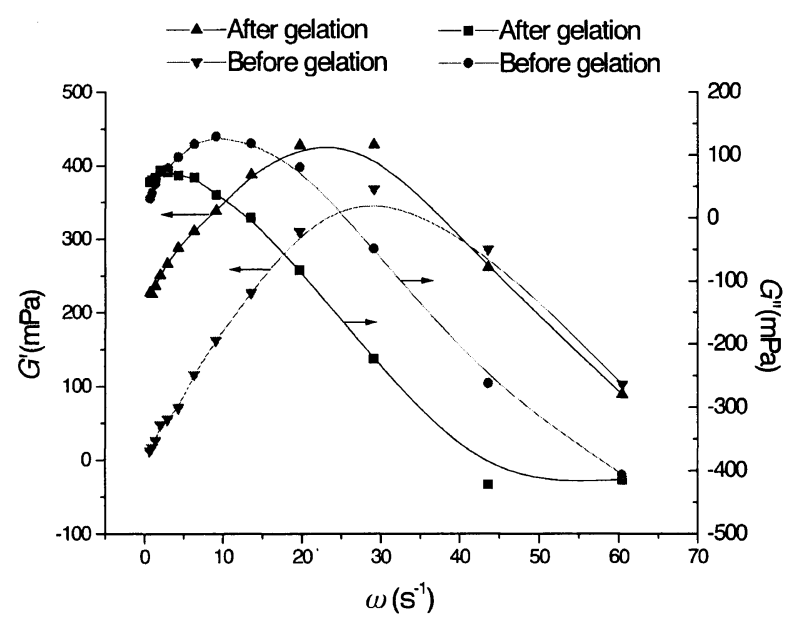

(b)

Figure 9. Comparison of viscoelastic properties of Ti(IV)-HPAM with HPAM dilute solution, (a) $G^{*}, \eta^{*}$, and $\omega$, (b) $G^{\prime}, G^{\prime \prime}$, and $\omega$.

$$
G^{*}=\tau_{0} / \gamma_{0}
$$

Where $\tau_{0}$ and $\gamma_{0}$ are the stress and strain amplitudes, respectively. It can also be defined as

$$
G^{*}=G^{\prime}+i G^{\prime \prime}
$$

Where $G^{\prime}$ and $G^{\prime \prime}$ are the storage modulus and loss modulus, respectively. Complex viscosity $\eta^{*}$ represents the total resistance to a dynamic shear:

$$
\eta^{*}=G^{*} / \omega
$$

Where $\omega$ is the frequency and $\eta^{*}$ is complex viscosity.

Figure 9 is the comparison of dynamic properties of Ti(IV)-HPAM gel with HPAM dilute solution, the concentration of HPAM is $400 \mathrm{ppm}$. Figure $9 \mathrm{a}$ shows that the $\eta^{*}$ of Ti(IV)-HPAM is greater than that of HPAM solution, both $\eta^{*}$ decrease with dynamic frequency, displaying a shear-thinning behavior. Figure $9 \mathrm{~b}$ shows that Ti( IV ) - HPAM gel and HPAM solution have increasing $G^{*}$ with increase of $\omega$, the $G^{*}$ of gel is greater than $G^{*}$ of
HPAM solution, which suggests that the higher the applied dynamic strain, the bigger resistance of the fluid, Ti(IV)-HPAM gel has stronger resistance to strain variation than polymer dilute solution. The $G^{\prime}$ and $G^{\prime \prime}$ curves of HPAM solution intersect at $\omega=26 \mathrm{~s}^{-1}$, indicating that HPAM solution has more elastic behavior at frequency higher than $26 \mathrm{~s}^{-1}$. For Ti(IV)-HPAM gel, $G^{\prime}$ and $G^{\prime \prime}$ curves intersect at $\omega=12 \mathrm{~s}^{-1}$, indicating that gel has predominant viscous behavior at frequency less than $12 \mathrm{~s}^{-1}$, at frequency higher than $12 \mathrm{~s}^{-1}$, the gel shows predominate elastic behavior.

\section{CONCLUSIONS}

The present study demonstrates that metal ion titanium(IV) can react with tartaric acid to form stable complexes. By varying the ratios of titanium to tartaric acid, the stability of titanium tartrate complexes can be controlled. The gelation between titanium(IV) and HPAM is a process of ligands exchange between tartaric acid and carboxyl groups of HPAM. Because of the slow releasing rate of Ti(IV) ions from titanium tartrate, the gelling of Ti(IV) with HPAM is delayed. Factors such as molar ratio of titanium to tartaric acid, polymer concentration, solution $\mathrm{pH}$ value, Ti(IV) concentration, solution salinity, and hydrolysis degree of HPAM have important influences on the Ti(IV)-HPAM gelation. The $\mathrm{pH}$ range for titanium-HPAM gelation is between $4.90-6.59$. With increase of titanium concentration, Ti(IV)-HPAM is gelling faster. When titanium tartrate concentration is more than $250 \mathrm{ppm}$, the formation of polynuclear complexes of titanium causes less effective crosslinking between titanium and HPAM, decreasing the gel strength. Salt sodium chloride increases the gelling rate. Ti(IV)HPAM gel shows shear thinning behavior during dynamic test. Comparing with HPAM gel crosslinked by other metal ion crosslinking agents, this titanium tartrate is adaptable to hard brine content, neutral $\mathrm{pH}$ condition and moderate temperature oil reservoirs.

\section{REFERENCES}

1. R. Deton, Adv. Colloid Interface Sci., 85, 1 (2000).

2. J. Zhang and N. A. Peppas, Macromolecules, 33, 102 (2000).

3. Y. Suetoh and M. Shibayama, Polymer, 41, 505 (2000).

4. A. Stavland and S. Nilsson, J. Pet. Sci. Eng., 13, 247 (1995).

5. C. G. Huang, D. W. Green, and G. P. Willhite, SPE Reservoir Eval. Eng., Nov., 583 (1986).

6. G. L. Cui, S. J. Xia, and Z. H. Xu, J. Petro. U China, 16(3), 40 (1992).

7. N. A. Mumallah, SPE Reservoir Eval. Eng., Feb., 243 (1988).

8. R. C. Fielding, Jr., D. H. Gbbons, and F. P. Legrand, SPE/ DOE, 27773, 433 (1994).

9. D. S. Robert, SPE Reservoir Eval. Eng., Aug., 346 (1990).

10. A. Moradi-Araghi, D. H. Beardmore, and G. A. Stahl, in "Water-Soluble Polymers for Petroleum Recovery", G. A. Stahl and D. N. Schulz, Ed., Plenum Publishing Corporation, New York, N.Y., 1988, p 299.

11. H. T. Dovan and R. D. Hutchins, SPE Reservoir Eval. Eng., May, 177 (1987).

12. G. Chauveteau, R. Tabary, M. Renard, and A. Omari, SPE, 50752, 507 (1999).

13. T. P. Lockhart, P. Albonico, and G. Burrafato, J. Appl. Polym. Sci., 43, 1527 (1991).

14. P. Albonico, G. Burrafato, and T. P. Lockhart, J. Polym. Sci., Part A: Polym. Chem., 30, 1071 (1992). 
15. L. Marty, D. W. Green, and G. P. Willhite, SPE Reservoir Eval. Eng., May, 219 (1991).

16. A. Omari, Polymer, 36, 815 (1995).

17. K. Sigale and A. Omari, J. Appl. Polym. Sci., 64, 1067 (1997).
18. M. P. Swamy, S. Bangaruswamy, J. N. Chatterjea, and J. B. Rao, Leather Science, 30, 291 (1983).

19. A. Moradi-Araghi, G. Bjornson, and P. H. Doe, SPE Advanced Technology Series, 1, 140 (1993). 